\title{
Nickel-Aluminum Oxide Aerogels: Super-adsorbents for Azo Dyes for Water Remediation
}

\author{
Maya Chaaban and Houssam El-Rassy*
}

Cite This: ACS Omega 2020, 5, 27401-27412

Read Online

ABSTRACT: Highly porous nickel-aluminum oxide aerogels were prepared according to a one-pot sol-gel process and dried under supercritical carbon dioxide conditions. Although the surface properties of these materials were very appealing for applications in catalysis, these aerogels were never applied in adsorption. The nickel effect on the structure and surface properties of the aerogels has been investigated via a broad range of structural, textural, and morphology characterization of the aerogels before and after heat treatment. The adsorption capacity of the assynthesized and calcined aerogels for azo dyes was assessed under various experimental conditions. The presence of nickel in the aerogel boosts tremendously the surface reactivity and improves noticeably the adsorption capacity of the material. The adsorption capacities for the nickel-aluminum oxide aerogel with $40 \%$ nickel $\left(q_{\max }\right)$ are $900 \mathrm{mg} \mathrm{g}^{-1}$ for methyl orange, $1484 \mathrm{mg} \mathrm{g}^{-1}$ for orange II, and $1660 \mathrm{mg} \mathrm{g}^{-1}$ for Congo Red. The adsorption process is exothermic and follows pseudo-second-order kinetics.

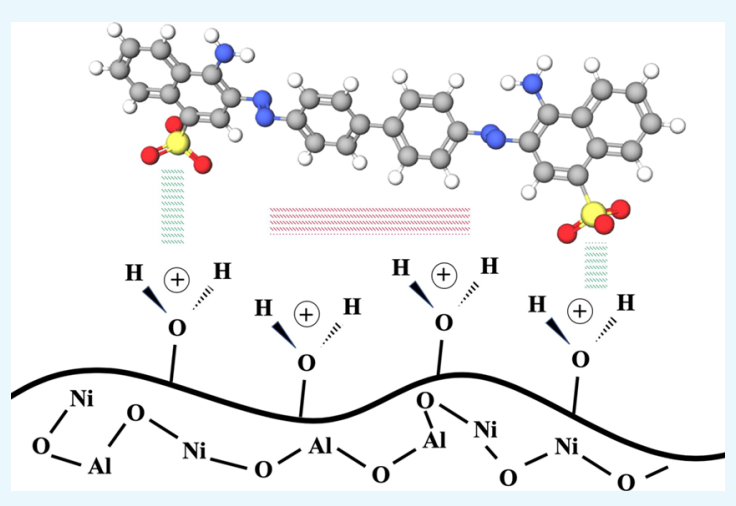

\section{INTRODUCTION}

Nickel-based materials have gained a lot of interest over the years because of their surface properties and relatively low cost. Alumina is one of the widely used solids as a support for catalytically active metals and metal oxides, among which are nickel and its oxide. Besides, alumina aerogels (AAs) synthesized via the sol-gel process ${ }^{1}$ followed by supercritical drying $^{2}$ are characterized by a highly porous inorganic network and are known for their high chemical and thermal stabilities. ${ }^{3}$ Although metal alkoxides were used for a long time as precursors for the synthesis of metal oxide gels, epoxideinitiated gelation is a relatively new approach that uses organic epoxides as proton scavengers and initiators for the polymerization of metal salts. ${ }^{4}$ The acidic metal complex obtained by the dissolution of the metal salt donates protons to the epoxide that undergoes ring-opening with the anion present in the medium. This leads to an increase in the $\mathrm{pH}$ of the solution, formation of aquo-hydroxy species ${ }^{5}$ that proceed to the condensation reactions of olation and oxolation, formation of the sol, and finally, condensation into a gel. ${ }^{2}$ Baumann et al. ${ }^{6}$ used this technique to prepare highly porous AAs starting from aluminum salts. Ren et al. ${ }^{7}$ showed an effect of the propylene oxide-to-aluminum ratio on the particle and pore sizes for AAs. Although the AAs were widely used as a support in catalysis, the application of these materials in adsorption was seldom investigated, where their use was limited to the adsorption of water vapor, ${ }^{8}$ pyridine, ${ }^{9}$ fluoride, ${ }^{10}$ and anionic azo dye. ${ }^{11} \mathrm{On}$ the other hand, nickel-aluminum oxide aerogels were of great interest for applications in catalysis for energy-related chemical processes. $^{12-17}$ Surprisingly, these materials were never reported as adsorbents in the literature, although the use of nickel oxide-based and alumina-based materials as adsorbents was investigated, more specifically for the removal of a few azo dyes from aqueous media. ${ }^{18-23}$

We investigate in the current study the synthesis of nickelaluminum oxide aerogels using the fast epoxide-initiated solgel method and their application as powerful adsorbents for three azo dyes from aqueous media. The structural and surface properties of the materials were investigated as a function of the nickel content, in addition to the correlation between these parameters and the adsorption capacity of the aerogels.

\section{EXPERIMENTAL SECTION}

2.1. Materials. The chemicals in this study were used as received and without any further purification. Aluminum nitrate nonahydrate $\mathrm{Al}\left(\mathrm{NO}_{3}\right)_{3} \cdot 9 \mathrm{H}_{2} \mathrm{O}$ was provided by $\mathrm{BDH}$. Nickel nitrate hexahydrate $\mathrm{Ni}\left(\mathrm{NO}_{3}\right)_{2} \cdot 6 \mathrm{H}_{2} \mathrm{O}$ and ethanol absolute were purchased from Sigma-Aldrich. Propylene oxide (noted PO; $\mathrm{CH}_{3} \mathrm{CHCH}_{2} \mathrm{O}$ ), orange II (noted OII, $\mathrm{C}_{16} \mathrm{H}_{11} \mathrm{~N}_{2} \mathrm{NaO}_{4} \mathrm{~S}$ ), methyl orange (noted MO,

Received: August 10, 2020

Accepted: October 6, 2020

Published: October 16, 2020 
$\mathrm{C}_{14} \mathrm{H}_{14} \mathrm{~N}_{3} \mathrm{NaO}_{3} \mathrm{~S}$ ), Congo Red (noted CR, $\mathrm{C}_{32} \mathrm{H}_{22} \mathrm{~N}_{6} \mathrm{Na}_{2} \mathrm{O}_{6} \mathrm{~S}_{2}$ ), methylene blue (noted $\mathrm{MB}$, $\mathrm{C}_{16} \mathrm{H}_{18} \mathrm{ClN}_{3} \mathrm{~S} \cdot x \mathrm{H}_{2} \mathrm{O}$ ), rhodamine $\mathrm{B}$ (noted rhB, $\mathrm{C}_{28} \mathrm{H}_{31} \mathrm{ClN}_{2} \mathrm{O}_{3}$ ), and rhodamine $6 \mathrm{G}$ (noted rh6G, $\mathrm{C}_{28} \mathrm{H}_{31} \mathrm{~N}_{2} \mathrm{O}_{3} \mathrm{Cl}$ ) were provided by Acros. Acetone was purchased from Scharlau Chemie S.A. Double distilled water was obtained from our laboratory.

2.2. Synthesis. In $7.64 \mathrm{~mL}$ of polypropylene microvials (from LAContainer), $0.539 \mathrm{~g}(1.44 \mathrm{mmol})$ of aluminum nitrate nonahydrate was dissolved in $2916 \mu \mathrm{L}$ of ethanol (49.94 mmol) under magnetic stirring. After the complete dissolution of the salt, $1060 \mu \mathrm{L}$ of propylene oxide (15.15 mmol) was added. The mixture was kept under stirring for a few seconds, after which it was left at rest. The formation of a gel was observed in the next 5-10 min, after which the gel was kept for aging for $24 \mathrm{~h}$ under ambient conditions. The gel was soaked in acetone for $24 \mathrm{~h}$, followed by a drying process in carbon dioxide under supercritical conditions $\left(T_{\mathrm{C}}=31.1{ }^{\circ} \mathrm{C}\right.$, $\left.P_{\mathrm{C}}=72.9 \mathrm{~atm}\right)$, leading to the so-called "alumina aerogel," noted AA. The final molar ratios for the $\mathrm{AA}$ were $\mathrm{Al}\left(\mathrm{NO}_{3}\right)_{3}$. $9 \mathrm{H}_{2} \mathrm{O} / \mathrm{EtOH} / \mathrm{PO}$ 1:34.7:10.5.

The preparation of the mixed oxide aerogel was performed by mixing aluminum nitrate nonahydrate and nickel nitrate hexahydrate with different molar ratios. The sum of the number of moles of the salts was $1.44 \mathrm{mmol}$. The mixture of aluminum and nickel salts was dissolved in ethanol and mixed to propylene oxide, as mentioned earlier. The obtained gels were dried under supercritical $\mathrm{CO}_{2}$, leading to the so-called "nickel-aluminum oxide aerogels," noted NAAs.

Different nickel-aluminum oxide aerogels were prepared, where the nickel molar content was 10 (noted NAA10), 20 (noted NAA20), 30 (noted NAA30), 40 (noted NAA40), 50 (noted NAA50), and 75\% (noted NAA75). It is worth noting that the preparation of the pure nickel oxide aerogel was not possible, according to this synthesis procedure.

All prepared alumina and nickel-aluminum oxide aerogels were used as-synthesized or after heat treatment. Calcination is performed in a muffle furnace under air at temperatures between 200 and $800{ }^{\circ} \mathrm{C}$ using a heating ramp rate of $2{ }^{\circ} \mathrm{C}$ $\mathrm{min}^{-1}$. The temperature was maintained at the desired value for $5 \mathrm{~h}$ before cooling.

2.3. Characterization. The porosity and surface area of the various AAs and NAAs were studied using the nitrogen adsorption-desorption technique on a NOVA 2200e highspeed surface area and pore size analyzer from Quantachrome Instruments. After degassing the samples for $3 \mathrm{~h}$ at $120^{\circ} \mathrm{C}$, the specific surface area (SSA) and the pore size and volume $\left(V_{\mathrm{p}}\right)$ were calculated according to the Brunauer-Emmett-Teller theory $^{24}$ and the Barrett-Joyner-Halenda method, ${ }^{25}$ respectively. Scanning electron microscopy (SEM) was performed on a TESCAN MIRA3 LMU electron microscope at $30 \mathrm{kV}$ equipped with an Oxford Instruments EDX detector. The samples were coated with a $5 \mathrm{~nm}$ layer of gold. The atomic absorption spectroscopy (AAS) analysis was performed by adding $100 \mathrm{mg}$ of each sample to a $5 \mathrm{~mL}$ mixture of strong acids $\mathrm{H}_{2} \mathrm{SO}_{4}$ and $\mathrm{HCl}$. The mixture was then treated in a microwave for $2 \mathrm{~h}$ to obtain a clear solution, before being analyzed for aluminum and nickel using a SOLAAR atomic absorption spectrophotometer equipped with an ASX-510 autosampler and G95 graphite furnace.

Fourier transform infrared (FTIR) spectroscopy in the $4000-400 \mathrm{~cm}^{-1}$ range was performed on a Thermo Nicolet 4700 FTIR spectrometer equipped with a Class 1 laser using the $\mathrm{KBr}$ pellet technique. Thermogravimetric analysis (TGA) was performed under air on a NETZSCH TG 209 F1 Iris with a heating rate of $5{ }^{\circ} \mathrm{C} \mathrm{min}^{-1}$. Powder X-ray diffraction patterns were recorded on a Bruker D8 ADVANCE X-ray diffractometer equipped with a $\mathrm{Cu} \mathrm{K} \alpha$ radiation source.

2.4. Adsorption Tests. The adsorption experiments were performed in glass reactors in a Julabo SW 23 shaking water bath at a controlled temperature under a constant shaking speed $(200 \mathrm{rpm})$. In a typical adsorption experiment, an initial amount of crushed alumina or nickel-aluminum oxide aerogels was added to a simulated wastewater containing a specific concentration of an organic dye. Aliquots were withdrawn at different time intervals over $4 \mathrm{~h}$, centrifuged at $13,300 \mathrm{rpm}$ in a Thermo Scientific Heraeus Pico 17 Microcentrifuge, and filtered on microfilters. The quantification of the concentration of the remaining dyes was performed using a Thermo Scientific Evolution $300 \mathrm{UV} / v i s / N I R$ spectrophotometer at wavelengths $\lambda=460,483$, and $500 \mathrm{~nm}$ for methyl orange, OII, and CR, respectively.

The effect on adsorption of nickel content, heat treatment, $\mathrm{pH}$, temperature, separation technique, and initial dye concentration was studied. The $\mathrm{pH}$ adjustment of the dye solutions was performed using $\mathrm{HCl}$ and $\mathrm{NaOH}$ solutions. The amount of the adsorbed dye was calculated as per the following equation

$$
q_{\mathrm{e}}=\frac{C_{0}-C_{\mathrm{e}}}{m} V
$$

where $q_{\mathrm{e}}$ is the amount of dye adsorbed at equilibrium ( $\mathrm{mg}$ $\left.\mathrm{g}^{-1}\right), C_{0}$ and $C_{\mathrm{e}}$ are the initial and equilibrium concentrations of the dye $\left(\mathrm{mg} \mathrm{L}^{-1}\right)$, respectively, $V$ is the volume of solution $(\mathrm{L})$, and $m$ is the amount of the adsorbent $(\mathrm{g})$.

\section{RESULTS AND DISCUSSION}

3.1. Characterization. 3.1.1. $N_{2}$ Adsorption-Desorption Isotherms. The nitrogen adsorption-desorption isotherms recorded for the alumina and nickel-aluminum oxide aerogels as-synthesized or after calcination revealed type-IV isotherms characterized by their hysteresis loops because of the nitrogen condensation within the mesopores, and the initial part is attributed to monolayer-multilayer adsorption. The aerogels also show $\mathrm{H} 3$ hysteresis loops associated with the metastability of the adsorbed multilayer, the low degree of pore curvature, and the nonrigidity of the aggregate structure. ${ }^{26}$ As examples of the adsorption-desorption isotherms, the Supporting Information (Figure S1) provides the isotherms recorded for AA and NAA75. All other aerogels exhibited similar profiles.

Table 1 shows the SSA and $V_{\mathrm{p}}$ calculated from the nitrogen isotherms for the various aerogels, either as-synthesized or after calcination at 200, 500, and $800{ }^{\circ} \mathrm{C}$. The as-synthesized AA possesses the highest SSA $\left(650 \mathrm{~m}^{2} \mathrm{~g}^{-1}\right)$ that decreases upon the increase in the nickel-to-aluminum molar ratio during the synthesis as well as with the increasing calcination temperature. These results are in agreement with what was previously reported. $^{27}$ Interestingly, increasing the calcination temperature decreases the pore volume linearly, regardless of the chemical composition of the aerogel (Figure 1).

This phenomenon might be due to a progressive densification coupled with a modification of the pore texture. As per the Oswald ripening-type process, micropores disappear while larger ones keep developing, resulting in a decrease of the overall pore volume. ${ }^{28}$ Besides, a linear decrease in the pore volume was observed for all nickel-aluminum oxide 
Table 1. SSA, Pore Volume $\left(V_{\mathrm{p}}\right)$, Average Pore Radius $\left(\boldsymbol{R}_{\mathrm{p}}\right)$, and Percentage of Pore Volume above the Kelvin Limit $\left(V_{\mathrm{p}, \mathrm{kel}}\right)$ Calculated for the Various As-Synthesized and Calcined Alumina and Nickel-Aluminum Oxide Aerogels

\begin{tabular}{|c|c|c|c|c|c|}
\hline sample & $\begin{array}{c}\text { calcination } \\
\text { temperature }\left({ }^{\circ} \mathrm{C}\right)\end{array}$ & $\begin{array}{c}\text { SSA } \\
\left(\mathrm{m}^{2} \mathrm{~g}^{-1}\right)\end{array}$ & $\left(\begin{array}{c}\left.V_{\mathrm{p}^{3}} \mathrm{~g}^{-1}\right) \\
\left(\mathrm{c}^{-1}\right.\end{array}\right.$ & $\begin{array}{l}R_{\mathrm{p}} \\
(\AA)\end{array}$ & $\begin{array}{l}V_{\mathrm{p}, \mathrm{kel}} \\
(\%)\end{array}$ \\
\hline \multirow{4}{*}{ AA } & as-synthesized & 650 & 4.46 & 137 & 99 \\
\hline & 200 & 482 & 3.81 & 158 & 99 \\
\hline & 500 & 255 & 3.46 & 271 & 100 \\
\hline & 800 & 269 & 3.20 & 238 & 100 \\
\hline \multirow[t]{4}{*}{ NAA10 } & as-synthesized & 519 & 1.95 & 75 & 94 \\
\hline & 200 & 305 & 1.58 & 104 & 98 \\
\hline & 500 & 274 & 1.49 & 108 & 97 \\
\hline & 800 & 208 & 1.72 & 165 & 99 \\
\hline \multirow[t]{4}{*}{ NAA20 } & as-synthesized & 581 & 1.94 & 67 & 94 \\
\hline & 200 & 336 & 1.46 & 87 & 97 \\
\hline & 500 & 276 & 1.32 & 96 & 97 \\
\hline & 800 & 219 & 1.16 & 107 & 98 \\
\hline \multirow[t]{4}{*}{ NAA30 } & as-synthesized & 474 & 1.70 & 72 & 96 \\
\hline & 200 & 399 & 1.37 & 69 & 95 \\
\hline & 500 & 298 & 1.47 & 99 & 98 \\
\hline & 800 & 231 & 0.99 & 86 & 97 \\
\hline \multirow[t]{4}{*}{ NAA40 } & as-synthesized & 472 & 1.54 & 65 & 94 \\
\hline & 200 & 329 & 1.17 & 71 & 95 \\
\hline & 500 & 304 & 1.22 & 80 & 97 \\
\hline & 800 & 225 & 1.08 & 96 & 97 \\
\hline \multirow[t]{4}{*}{ NAA50 } & as-synthesized & 486 & 1.36 & 56 & 93 \\
\hline & 200 & 347 & 1.30 & 75 & 96 \\
\hline & 500 & 273 & 1.17 & 86 & 98 \\
\hline & 800 & 178 & 1.04 & 117 & 98 \\
\hline \multirow[t]{4}{*}{ NAA75 } & as-synthesized & 188 & 0.88 & 93 & 95 \\
\hline & 200 & 197 & 0.75 & 76 & 94 \\
\hline & 500 & 123 & 0.64 & 104 & 94 \\
\hline & 800 & 124 & 0.56 & 90 & 96 \\
\hline
\end{tabular}

aerogels when increasing the nickel content. This was observed for the as-synthesized aerogels and for those calcined at 200 ${ }^{\circ} \mathrm{C}$; however, calcination at higher temperatures did not show a clear linear trend in the change of the pore volumes.

The percent of the pore volume above the Kelvin limit $\left(V_{\mathrm{p}, \mathrm{kel}}\right)$, corresponding to mesopores, reveals the dominant mesoporous nature of the aerogels. Because the decrease in the SSA was more significant than for the $V_{\mathrm{p}}$, the pore radii $\left(R_{\mathrm{p}}\right)$ increase as the calcination temperature increases. This is due to the sintering of the inorganic network upon heat treatment.

3.1.2. Scanning Electron Microscopy. The SEM micrographs for the alumina and nickel-aluminum oxide aerogels revealed their porous structure composed of agglomerates of spherical particles (Figure 2). The micrographs showed no noticeable variations in the surface morphology of the aerogels upon calcination or increase in the nickel content. Even though the variation in the SSA and $V_{\mathrm{p}}$ values could not be concluded from the micrographs, the aggregate structure observed confirms the type $\mathrm{H} 3$ hysteresis, as seen in the nitrogen adsorption-desorption isotherms.

3.1.3. Atomic Absorption Spectroscopy. The elemental composition of the various aerogels was determined by AAS. The weight percent of each element was calculated as per the following equation

$$
\text { weight } \% \text { of element }=\frac{\text { mass of the element }}{\text { mass of the aerogel }} \times 100
$$
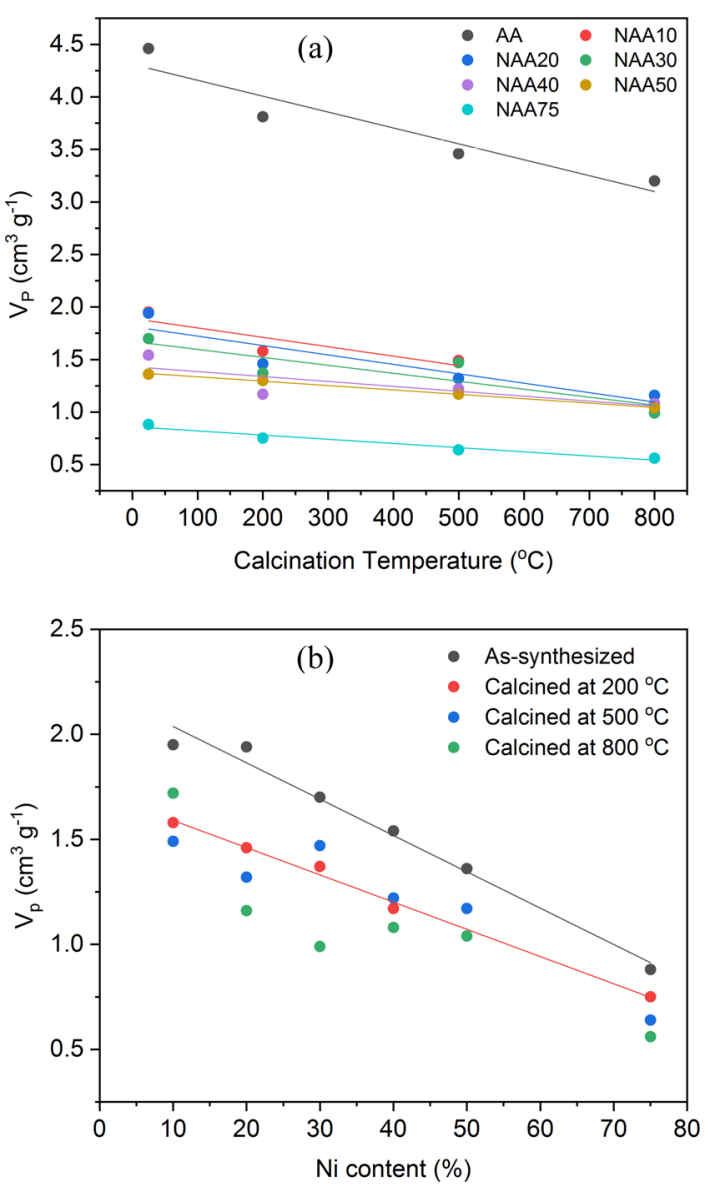

Figure 1. Effect of (a) calcination and (b) nickel content on the pore volume $\left(V_{\mathrm{p}}\right)$ of alumina and nickel-aluminum oxide aerogels.

The molar percent, molar ratio, and weight ratio of each element were calculated according to the following

$$
\text { molar } \% \text { of element }=\frac{\text { weight } \% \text { of element }}{\text { molecular weight of the element }}
$$

molar nickel ratio

$$
=\frac{\text { molar } \% \text { of nickel }}{\text { molar } \% \text { of nickel }+ \text { molar } \% \text { of aluminum }}
$$

weight nickel ratio

$$
=\frac{\text { weight } \% \text { of nickel }}{\text { weight } \% \text { of nickel }+ \text { weight } \% \text { of aluminum }}
$$

The data given in the Supporting Information (Table S1) show that the calculated nickel-to-aluminum ratio was always higher than the theoretical/expected value for all NAAs except NAA75. This indicates that the co-incorporation of nickel and aluminum elements within the network does not take place in the same way. The plot of the experimental versus theoretical nickel content (Figure 3 ) shows perfect linearity between $0 \%$ $\mathrm{Ni}$ (AA) and $30 \% \mathrm{Ni}$ (NAA30), where the experimental-totheoretical Ni content ratio is almost 1.30 . This ratio is almost constant and greater than 1.00, which means that the reaction of the nickel aqua complex with the epoxide ${ }^{4}$ as well as the olation and oxolation reactions ${ }^{2}$ favor the inclusion of the nickel atoms within the metal oxide network more than the aluminum atoms. The nonintegrated aluminum atoms will be 

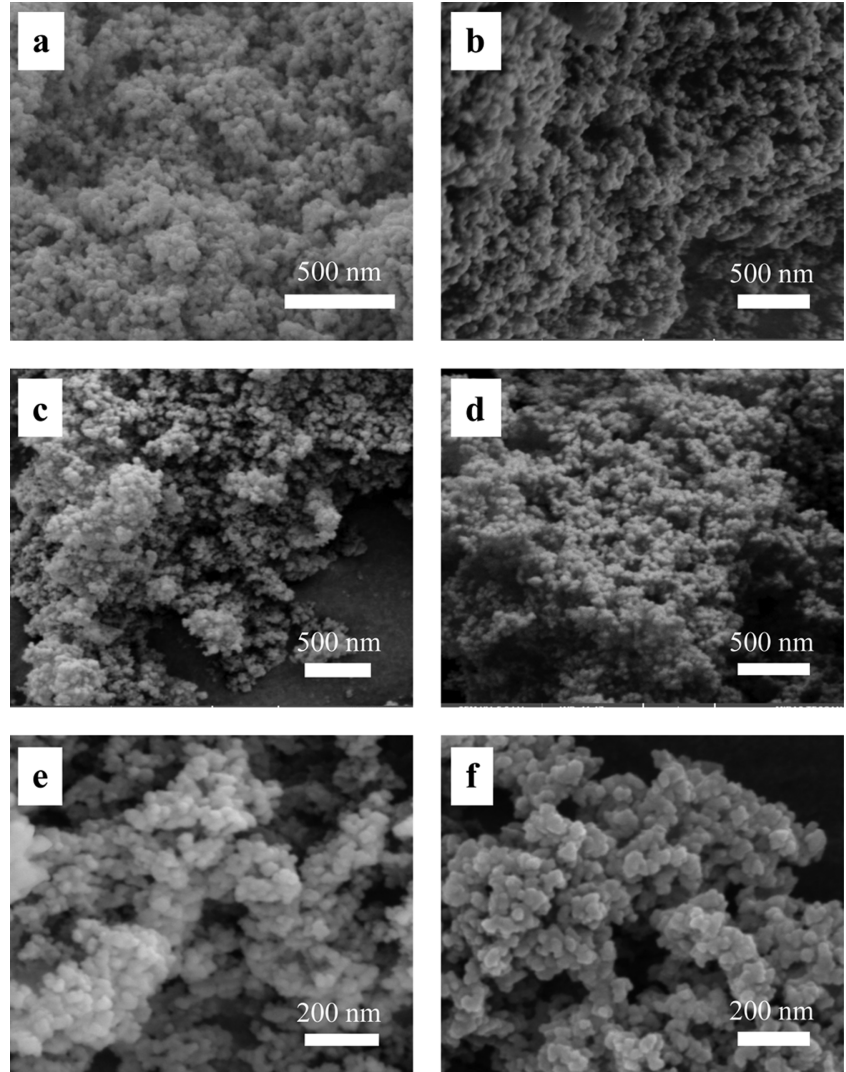

Figure 2. SEM micrographs of (a) as-synthesized AA; (b) AA calcined at $200{ }^{\circ} \mathrm{C}$; (c) AA calcined at $500^{\circ} \mathrm{C}$; (d) AA calcined at 800 ${ }^{\circ} \mathrm{C}$; (e) NAA40 calcined at $200{ }^{\circ} \mathrm{C}$; and (f) as-synthesized NAA50.

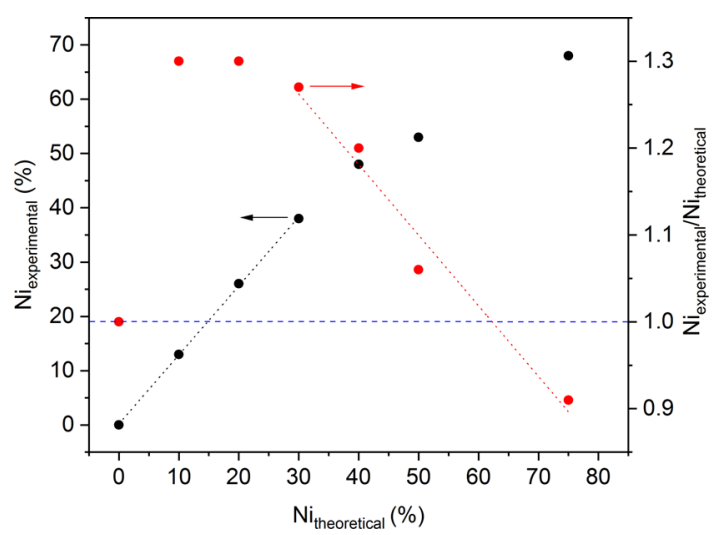

Figure 3. Comparison of the experimental vs theoretical nickel content for alumina and nickel-aluminum oxide aerogels. The blue dashed line represents the theoretical $\mathrm{Ni}_{\text {experimental }} / \mathrm{Ni}_{\text {theoretical }}$ ratio of 1 .

washed out of the gel during the solvent exchange and drying steps. The decrease in the ratio below unity for NAA75 could be due to the nonfavored formation of metal-oxygen bonds at high concentrations of nickel, which makes the nickel aqua complexes less involved in metal oxo-bridged structures. This behavior is much more expressed when nickel is solely used in the synthesis, where we noticed that no pure nickel oxide aerogel can be formed.

3.1.4. FTIR Spectroscopy. The FTIR spectra of the assynthesized and calcined alumina and nickel-aluminum oxide aerogels are presented in the Supporting Information (Figure S2). All spectra show common bands between 3500 and 3000
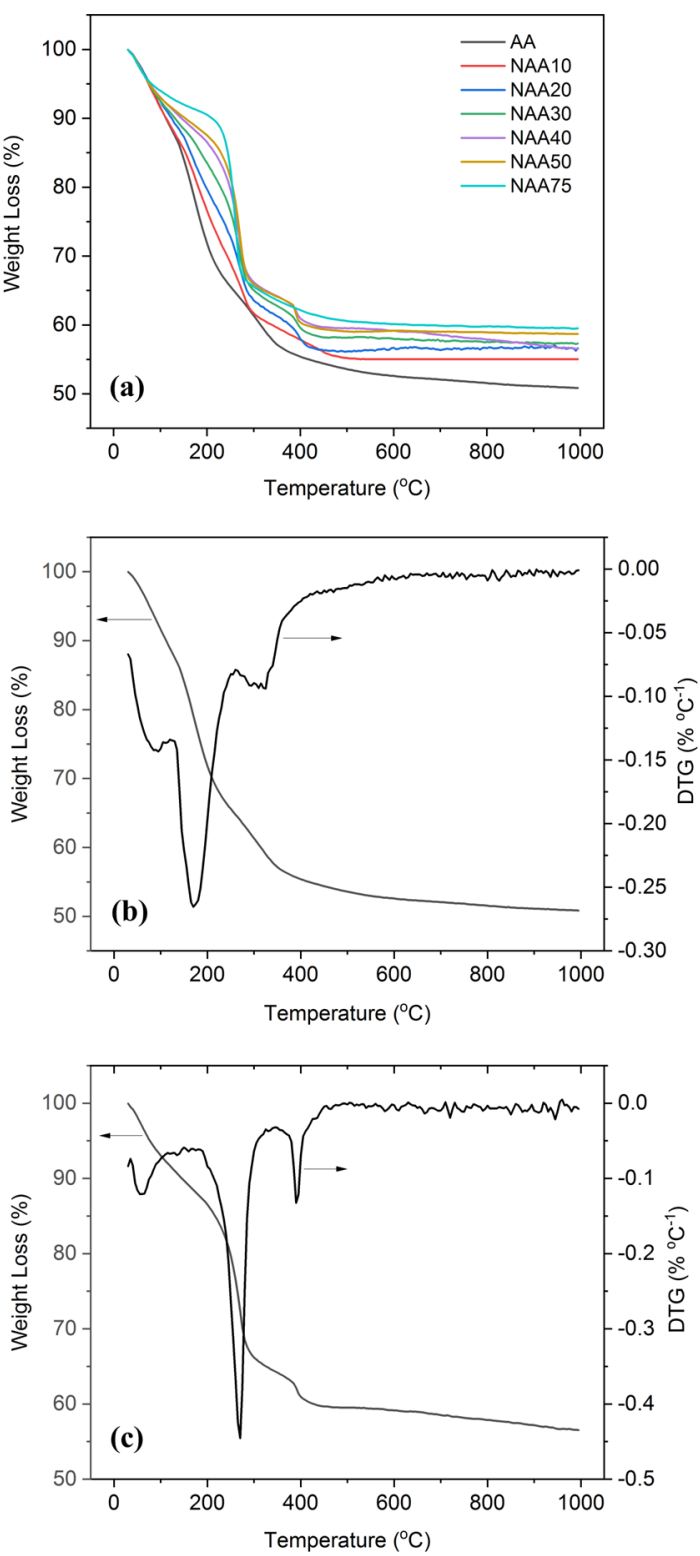

Figure 4. (a) TGA curves for the as-synthesized alumina and nickelaluminum oxide aerogels; TGA and DTG for (b) AA and (c) NAA40.

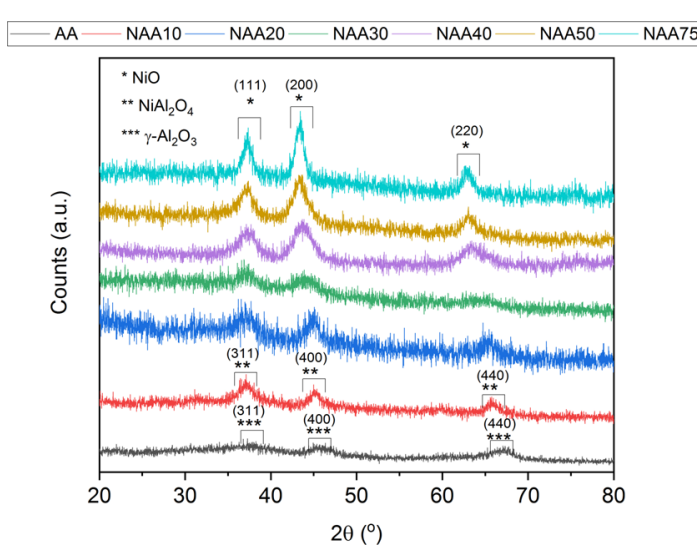

Figure 5. Powder X-ray diffractograms for alumina and nickelaluminum oxide aerogels calcined at $800{ }^{\circ} \mathrm{C}$. 

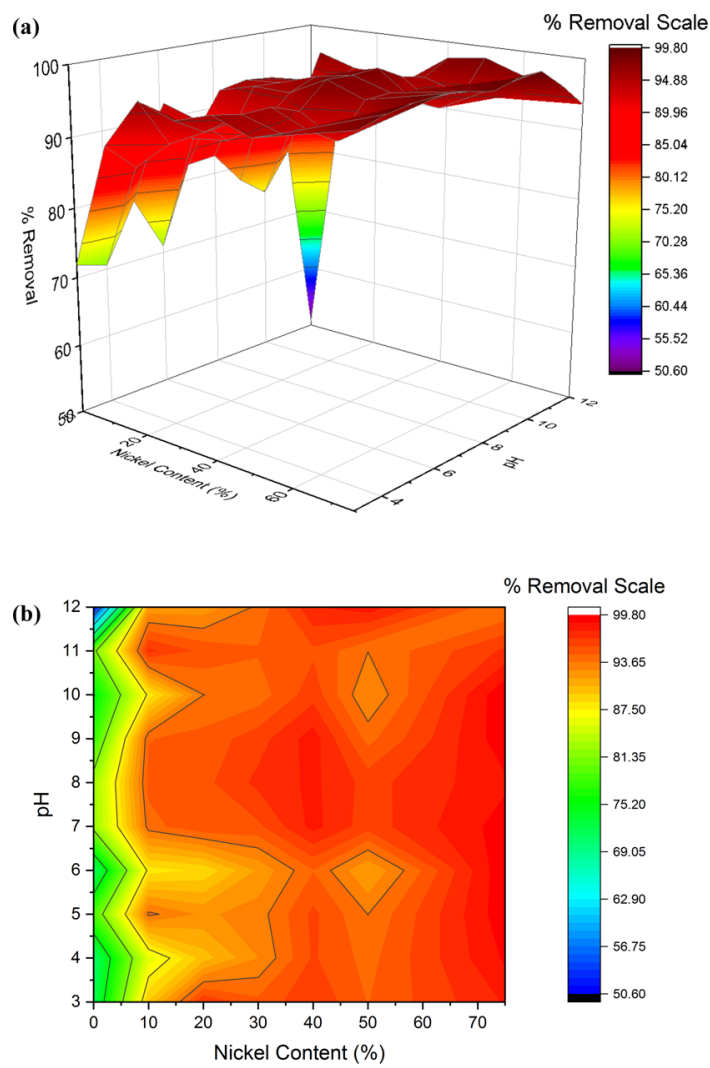

Figure 6. (a) 3D color map and (b) contour of the adsorption of OII as a function of the $\mathrm{pH}$ of the solution and the nickel content of the aerogels. Adsorbent mass $=25 \mathrm{mg}$, initial OII concentration $=50$ ppm, contact time $=4 \mathrm{~h}, \mathrm{~T}=30^{\circ} \mathrm{C}$, and solution volume $=20 \mathrm{~mL}$.

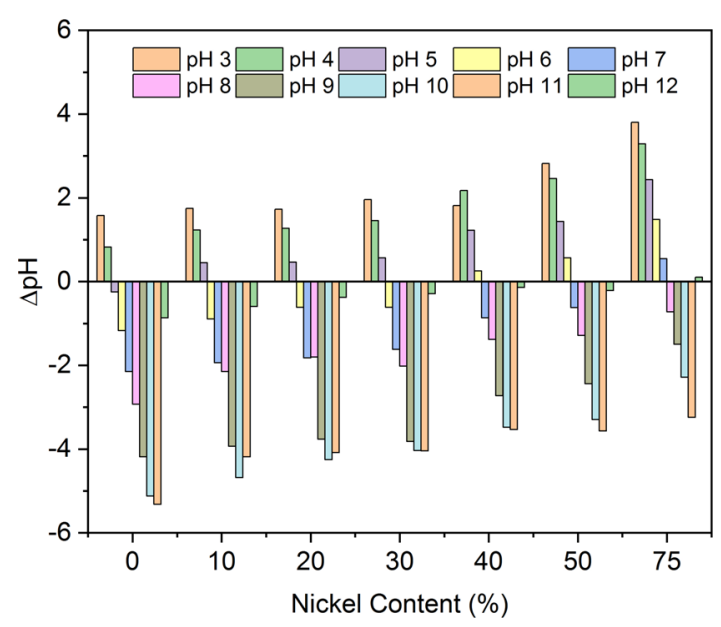

Figure 7. $\mathrm{pH}$ variation of the dye solution at the end of the adsorption experiments. Adsorbent mass $=25 \mathrm{mg}$, initial OII concentration $=50$ $\mathrm{ppm}$, contact time $=4 \mathrm{~h}, \mathrm{~T}=30^{\circ} \mathrm{C}$, and solution volume $=20 \mathrm{~mL}$.

$\mathrm{cm}^{-1}$, attributed to the $\mathrm{OH}$ stretching of hydrogen-bonded water molecules and MO-H stretching. ${ }^{21}$ The presence of the surface $\mathrm{OH}$ groups is also depicted by the peaks appearing at around $1630 \mathrm{~cm}^{-1}$, attributed to their deformation vibrations. $^{29}$ The bands appearing at 2975 and $2935 \mathrm{~cm}^{-1}$ for the as-synthesized aerogels correspond to the $\mathrm{C}-\mathrm{H}$ symmetric and asymmetric stretching of the residual $\mathrm{CH}_{2}$ and $\mathrm{CH}_{3}$ groups. These peaks almost disappear from the spectra of the aerogels after heat treatment because of the chemical decomposition of

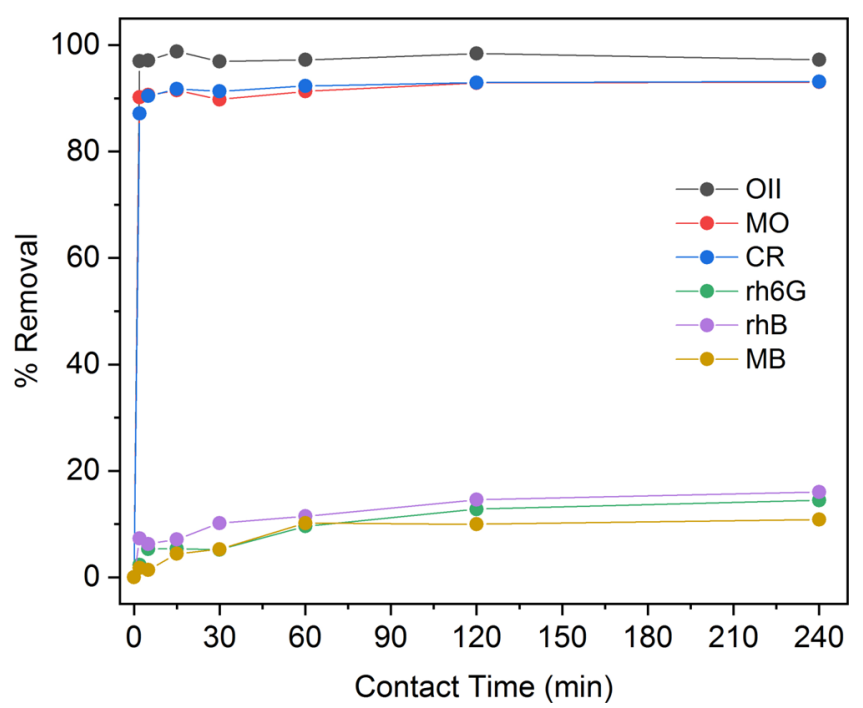

Figure 8. Adsorption of different cationic and anionic dyes on the assynthesized NAA75. Adsorbent mass $=25 \mathrm{mg}$, initial dye concentration $=50 \mathrm{ppm}, T=30^{\circ} \mathrm{C}$, and solution volume $=20 \mathrm{~mL}$.

Table 2. Metal Release into the Aqueous Medium during the Adsorption of OII onto As-Synthesized NAA40 ${ }^{a}$

\begin{tabular}{|c|c|c|c|c|}
\hline \multirow[b]{2}{*}{$\mathrm{pH}$} & \multicolumn{2}{|c|}{$\%$ release of nickel } & \multicolumn{2}{|c|}{$\%$ release of aluminum } \\
\hline & after $2 \mathrm{~min}$ & after $240 \mathrm{~min}$ & after $2 \mathrm{~min}$ & after $240 \mathrm{~min}$ \\
\hline 3 & 7 & 18 & 0 & 0 \\
\hline 4 & 5 & 9 & 0 & 0 \\
\hline 6 & 7 & 9 & 0 & 0 \\
\hline 7 & 6 & 11 & 0 & 0 \\
\hline 8 & 2 & 5 & 0 & 0 \\
\hline 9 & 3 & 5 & 0 & 0 \\
\hline 10 & 4 & 6 & 0 & 0 \\
\hline 11 & 0 & 0 & 0 & 4 \\
\hline 12 & 0 & 0 & 27 & 47 \\
\hline
\end{tabular}

${ }^{a}$ Adsorbent mass $=25 \mathrm{mg}$, initial OII concentration $=50 \mathrm{ppm}, T=30$ ${ }^{\circ} \mathrm{C}$, and solution volume $=20 \mathrm{~mL}$.

any residual epoxide inside the porosity of the gel or on its surface. This is also verified by the gradual decrease in the intensity of the peaks appearing at around $1384 \mathrm{~cm}^{-1}$, attributed to the $\mathrm{C}-\mathrm{H}$ symmetric deformation upon calcination. The spectra reveal the characteristic broad composed bands that are related to the $\mathrm{Al}-\mathrm{O}$ vibrations with the poor distinction of their maxima appearing at around 923,870 , and $833 \mathrm{~cm}^{-1}$. The presence of nickel is depicted by the $\mathrm{Ni}-\mathrm{O}$ stretching vibrations appearing at around 560 $\mathrm{cm}^{-1} \cdot{ }^{21}$

3.1.5. Thermogravimetric Analysis. The weight loss of the various aerogels due to heat treatment has been followed by TGA between room temperature and $1000{ }^{\circ} \mathrm{C}$. The recorded curves, as well as their first derivatives (DTG), show distinct temperature ranges where losses took place (Figure 4 ). The first weight loss between room temperature and $125^{\circ} \mathrm{C}$ with a maximum loss at $T_{\max } 95^{\circ} \mathrm{C}$ (for AA) is attributed to the loss of the water molecules adsorbed on the surface of the aerogels and some residual solvent from the synthesis. ${ }^{30} T_{\max }$ gradually shifts to lower temperatures with the increasing nickel content $\left(T_{\max }=50{ }^{\circ} \mathrm{C}\right.$ for NAA75). This suggests a weaker interaction of the water molecules with the surface of the solid upon the increasing nickel content. The second weight loss is seen at 


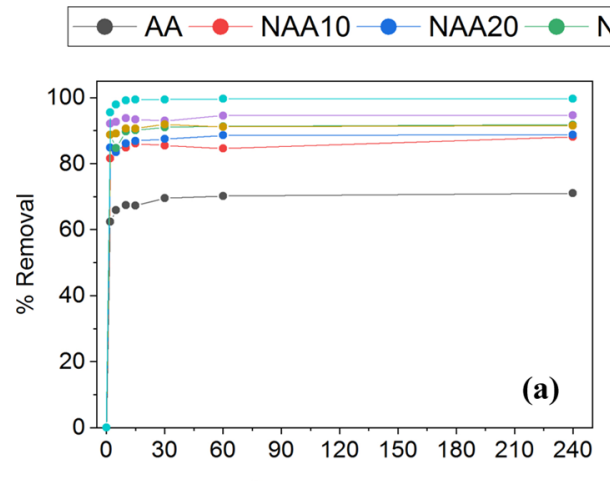

NAA30 $\bullet$ NAA40 $\bullet$ NAA50 $\bullet$ NAA75
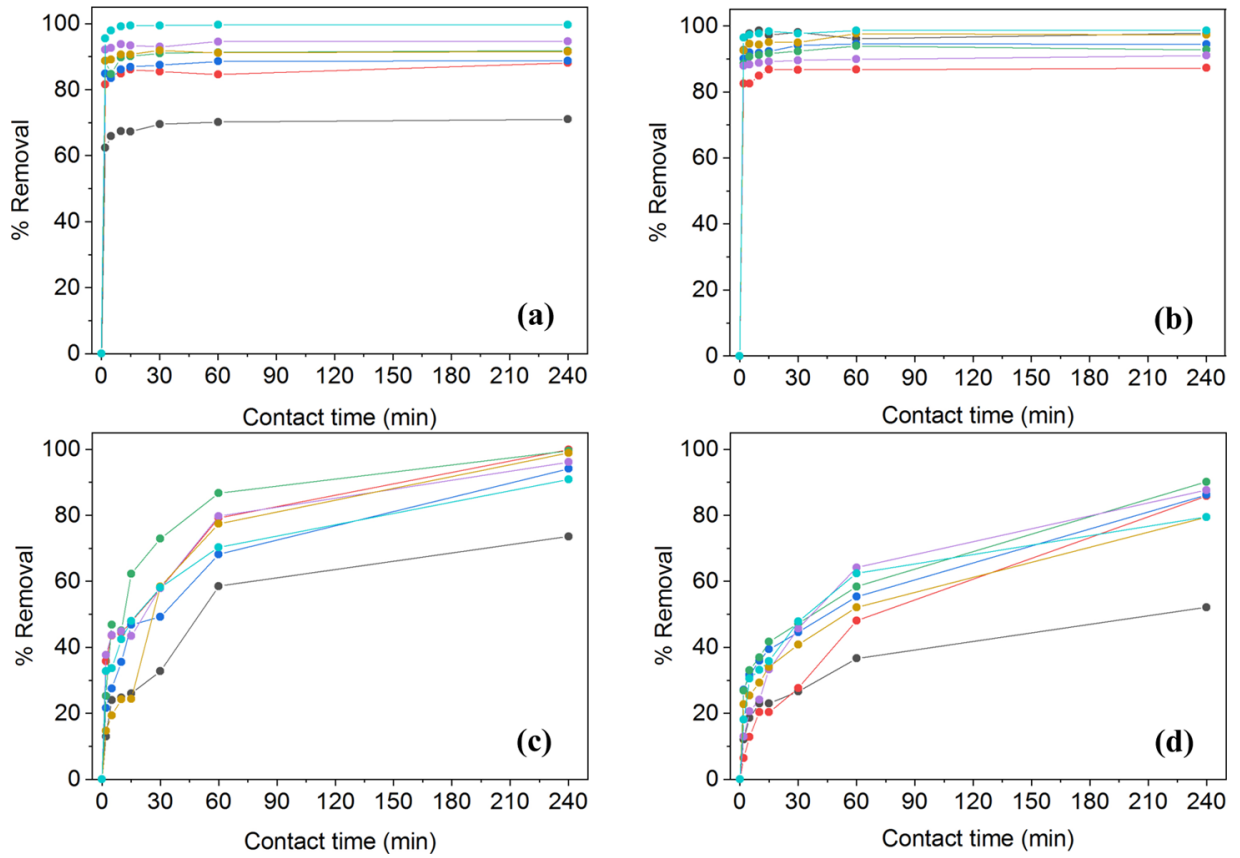

Figure 9. OII removal as a function of time onto (a) as-synthesized; (b) calcined at $200{ }^{\circ} \mathrm{C}$; (c) calcined at $500{ }^{\circ} \mathrm{C}$; and (d) calcined at $800{ }^{\circ} \mathrm{C}$. Adsorbent mass $=25 \mathrm{mg}$, initial OII concentration $=50 \mathrm{ppm}, T=30^{\circ} \mathrm{C}$, solution volume $=20 \mathrm{~mL}$.

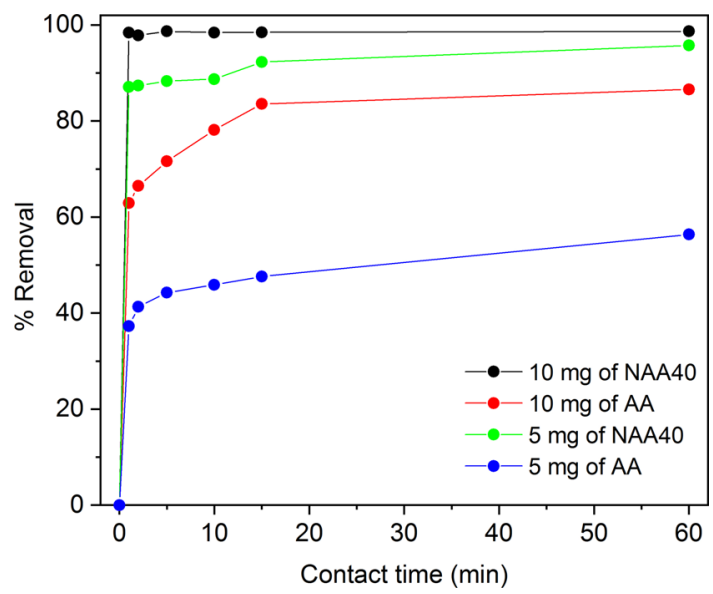

Figure 10. Effect of mass of the as-synthesized adsorbent on OII removal. Initial OII concentration $=50 \mathrm{ppm}, \mathrm{pH}=8, T=30^{\circ} \mathrm{C}$, and solution volume $=40 \mathrm{~mL}$.

temperatures below $260{ }^{\circ} \mathrm{C}$ with a maximum degradation at around $170-190{ }^{\circ} \mathrm{C}$. This weight loss is attributed to the oxidation of $\mathrm{C}-\mathrm{H}$ bonds present in the inorganic structure and confirmed by FTIR spectroscopy. The quantification of the weight loss for the various as-synthesized aerogels shows that the percent weight remaining after this degradation increases with the increasing nickel content. The third weight loss extends to around $340{ }^{\circ} \mathrm{C}$ with a $T_{\max }$ at $270{ }^{\circ} \mathrm{C}$ for all aerogels except for AA, where $T_{\max }$ appears at a higher temperature. This weight loss is attributed to the oxidation of any residual organic molecule within the pores of the network, ${ }^{31}$ such as propylene oxide and its relative products generated during the formation of the inorganic network. The absence of these chemicals in the AA could be attributed to its large pore volume, allowing easy removal of these chemicals from the pores during the solvent exchange and the drying steps. The fourth weight observed for higher temperatures with $T_{\max }$ around $390{ }^{\circ} \mathrm{C}$ is attributed to the slow liberation of structure water coupled with the loss of the structure hydroxide groups, leading to the nickel-aluminum oxide. ${ }^{32}$ Consequently, the TGA confirms the thermal stability of the prepared aerogels after heat treatment at high temperatures.

3.1.6. Powder X-ray Diffraction. The powder X-ray diffractograms recorded between 20 and $80^{\circ}$ for the assynthesized aerogels did not show any peak, revealing the amorphous nature of these materials. The same was observed after the heat treatment of the aerogels at 200 and $500{ }^{\circ} \mathrm{C}$, except for NAA50 and NAA75 that showed broad diffraction lines when calcined at $500{ }^{\circ} \mathrm{C}$ (Supporting Information Figure S3). These lines correspond to the (111), (200), and (220) planes of nickel oxide $\mathrm{NiO}$. The diffractograms of the heated aerogels at $800{ }^{\circ} \mathrm{C}$ show diffraction peaks for all aerogels, revealing the chemical nature of the solid material (Figure 5). For instance, $\gamma-\mathrm{Al}_{2} \mathrm{O}_{3}$ was found in the $\mathrm{AA}$ with its distinct planes (311), (400), and (440) at 38.1, 45.8, and 67.2 respectively. The nickel aluminate spinel structure $\mathrm{NiAl}_{2} \mathrm{O}_{4}$ was observed when nickel and aluminum co-exist at a low nickel-to-aluminum molar ratio (NAA10 and NAA20). The diffraction planes for $\mathrm{NiAl}_{2} \mathrm{O}_{4}$ are comparable to $\gamma-\mathrm{Al}_{2} \mathrm{O}_{3}$; however, they appear with a shift to lower $2 \theta$. NAA30 exhibits broad peaks that are observed with the overlapping of the $\mathrm{NiAl}_{2} \mathrm{O}_{4}$ peaks and those of $\mathrm{NiO}$ appearing at smaller $2 \theta$ values. The diffraction peaks observed for NAA40 at 37.3, 43.8, and 63.4 correspond to the (110), (200), and (220) planes of $\mathrm{NiO}$. The shift in these peaks to slightly lower $2 \theta$ with the increasing nickel-to-aluminum molar ratio for NAA50 and NAA75 suggests that these diffraction peaks are the results of the overlapping of peaks from $\mathrm{NiO}$ and $\mathrm{NiAl}_{2} \mathrm{O}_{4}$, where $\mathrm{NiO}$ becomes more expressed as the molar ratio increases. Besides, the comparison of these peaks to those observed for the same 
Table 3. Langmuir, Freundlich, Dubinin-Radushkevich, Redlich-Peterson, and Sips Isotherm Constants Compiled for the As-Synthesized AA and NAA40

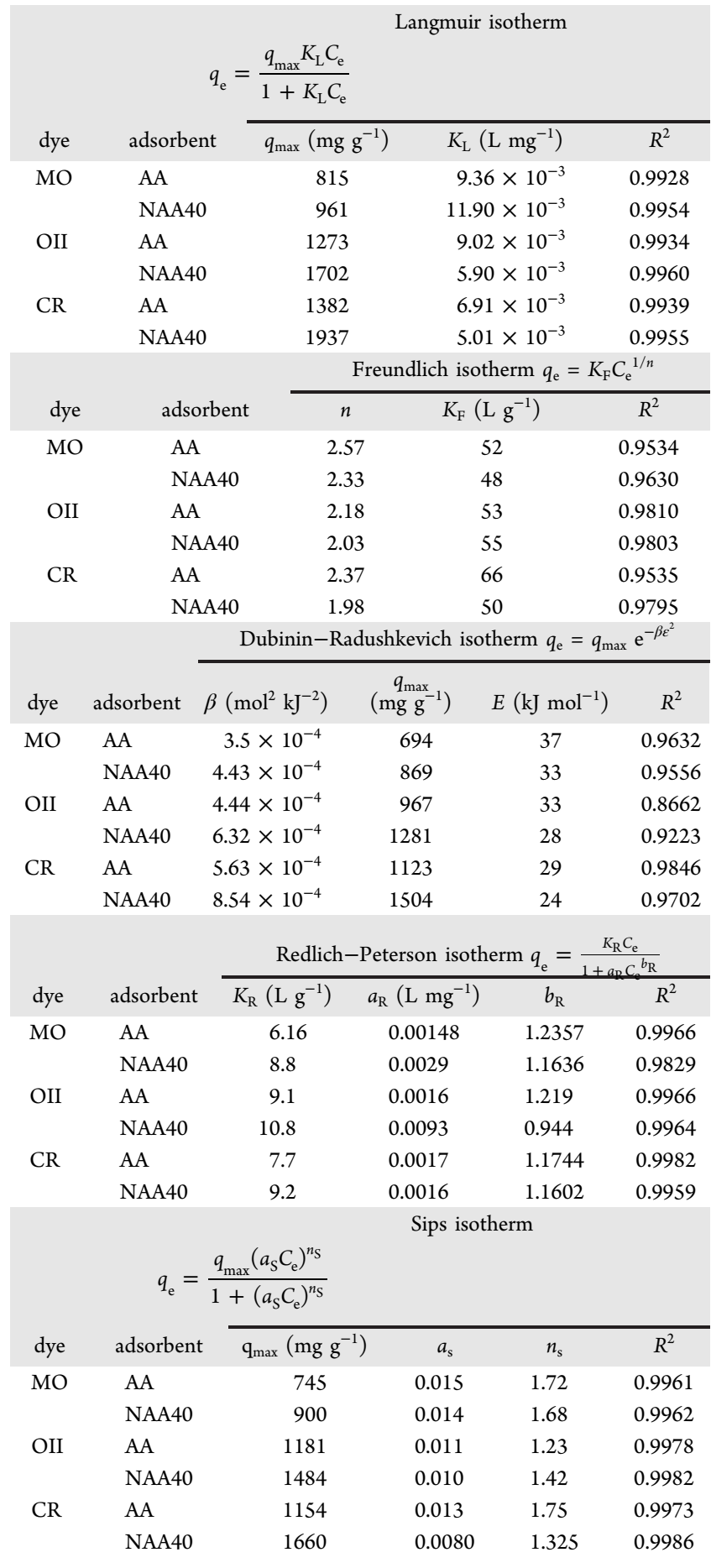

materials heated at $500{ }^{\circ} \mathrm{C}$ shows that at the higher temperature, they appear sharper and narrower, thus indicating a better crystallinity. These findings show that the increase in the nickel content in these heat-treated aerogels makes the dominant phase to shift from $\gamma-\mathrm{Al}_{2} \mathrm{O}_{3}$ for the AA to nickel aluminate at low nickel-to-aluminum molar ratios and to nickel oxide at high nickel-to-aluminum molar ratios. A visual confirmation of these findings was the blue color of NAA10 characteristic of spinel nickel aluminate that becomes bluegreen as the nickel content increases. The dominant green
Table 4. Comparison of the Maximum Monolayer Adsorption Capacities $\left(q_{\max }\right)$ of AA and NAA40 Aerogels with the Previously Reported Adsorbents for Azo Dyes in the Literature

\begin{tabular}{|c|c|c|c|}
\hline dye & adsorbent & $\underset{\left(\mathrm{mg} \mathrm{g}^{-1}\right)}{q_{\max }}$ & references \\
\hline \multirow[t]{13}{*}{ OII } & $\begin{array}{l}\text { coordination polymer }[\mathrm{Cu}(\text { bipy }) \\
\left.\left(\mathrm{SO}_{4}\right)\right]_{n}\end{array}$ & $\begin{array}{l}3308 \\
\left(27^{\circ} \mathrm{C}\right)\end{array}$ & 41 \\
\hline & $N$-vinyl imidazole-based hydrogels & $\begin{aligned} 2331 \\
\left(25{ }^{\circ} \mathrm{C}\right)\end{aligned}$ & 42 \\
\hline & magnolia leaf-based porous carbon & $\stackrel{1488}{\left(25{ }^{\circ} \mathrm{C}\right)}$ & 43 \\
\hline & NAA40 aerogel & $\left.\stackrel{1484}{(30}{ }^{\circ} \mathrm{C}\right)$ & this work \\
\hline & $\mathrm{Mg}_{\mathrm{R}} \mathrm{AlNO}_{3}$-layered double hydroxides & ${ }^{1263}\left(40{ }^{\circ} \mathrm{C}\right)$ & 44 \\
\hline & $\begin{array}{l}\text { cellulose biotemplates for LDH } \\
\text { networks }\end{array}$ & $\begin{array}{l}1190 \\
\left(20^{\circ} \mathrm{C}\right)\end{array}$ & 45 \\
\hline & AA aerogel & ${ }^{1181}\left(30^{\circ} \mathrm{C}\right)$ & this work \\
\hline & $\mathrm{Ti}^{4+}$ cross-linked chitosan & ${ }^{1120}\left(25^{\circ} \mathrm{C}\right)$ & 46 \\
\hline & clam shell & ${ }^{1017}\left(13^{\circ} \mathrm{C}\right)$ & 47 \\
\hline & graphene aerogels & $598\left(25^{\circ} \mathrm{C}\right)$ & 48 \\
\hline & iron-benzenetricarboxylate MOF & $438\left(25^{\circ} \mathrm{C}\right)$ & 49 \\
\hline & iron-benzenetricarboxylate MOF & $438\left(25{ }^{\circ} \mathrm{C}\right)$ & 49 \\
\hline & titania aerogels & $402\left(30^{\circ} \mathrm{C}\right)$ & 50 \\
\hline \multirow[t]{9}{*}{ MO } & $\begin{array}{l}\text { organometallic functionalized } \\
\mathrm{SiO}_{2}-\mathrm{Al}_{2} \mathrm{O}_{3}\end{array}$ & $\stackrel{1695}{\left(25^{\circ} \mathrm{C}\right)}$ & 51 \\
\hline & $\begin{array}{l}\text { coordination polymer }[\mathrm{Cu}(\text { bipy }) \\
\left.\left(\mathrm{SO}_{4}\right)\right]_{n}\end{array}$ & ${ }^{1521}\left(27^{\circ} \mathrm{C}\right)$ & 41 \\
\hline & NAA40 aerogel & $900\left(30^{\circ} \mathrm{C}\right)$ & this work \\
\hline & magnolia leaf-based porous carbon & $869\left(25^{\circ} \mathrm{C}\right)$ & 43 \\
\hline & $\begin{array}{l}\text { CoAl-layered double hydroxide } \\
\text { nanosheets }\end{array}$ & 828 & 52 \\
\hline & AA aerogel & $745\left(30^{\circ} \mathrm{C}\right)$ & this work \\
\hline & PCN-222 MOF & $591\left(25^{\circ}\right)$ & 53 \\
\hline & 3D hierarchical GO-NiFe LDH & 438 & 54 \\
\hline & $\begin{array}{l}\text { carboxymethyl chitosan/gelatin } \\
\text { microspheres }\end{array}$ & 383 & 55 \\
\hline \multirow[t]{10}{*}{$\mathrm{CR}$} & NAA40 aerogel & ${ }^{1660}\left(30^{\circ} \mathrm{C}\right)$ & this work \\
\hline & AA aerogel & $\begin{aligned} 1154 \\
(30\end{aligned}$ & this work \\
\hline & $\begin{array}{l}\text { cauliflower-like } \mathrm{Ni} / \mathrm{NiO} \text { and } \mathrm{NiO} \\
\text { architectures }\end{array}$ & $642\left(25{ }^{\circ} \mathrm{C}\right)$ & 22 \\
\hline & $\mathrm{NiO}$ hollow microspheres & $526\left(25{ }^{\circ} \mathrm{C}\right)$ & 18 \\
\hline & $\gamma-\mathrm{Al}_{2} \mathrm{O}_{3}$ nanorods & $416\left(25^{\circ} \mathrm{C}\right)$ & 20 \\
\hline & hierarchical $\mathrm{NiO}-\mathrm{Al}_{2} \mathrm{O}_{3}$ & $357\left(30^{\circ} \mathrm{C}\right)$ & 21 \\
\hline & $\gamma-\mathrm{Al}_{2} \mathrm{O}_{3}$ hollow microspheres & $322\left(25^{\circ} \mathrm{C}\right)$ & 19 \\
\hline & hierarchical $\mathrm{NiO}$ & $250\left(30{ }^{\circ} \mathrm{C}\right)$ & 21 \\
\hline & $\mathrm{Al}_{2} \mathrm{O}_{3}$ & $164\left(30^{\circ} \mathrm{C}\right)$ & 21 \\
\hline & $\mathrm{NiO} /$ graphene nanosheets & $124\left(25{ }^{\circ} \mathrm{C}\right)$ & 23 \\
\hline
\end{tabular}

color characteristic of nickel oxide is observed for NAA40, NAA50, and NAA75 (Supporting Information Figure S4).

3.2. Adsorption Study. 3.2.1. Effect of $\mathrm{pH}$ and Nickel Content on Adsorption. The effect on adsorption of the $\mathrm{pH}$ of the simulated wastewater solution and the nickel content in the aerogels was investigated for the as-synthesized aerogels. OII was selected as a dye, and the $\mathrm{pH}$ range was varied between 3 and 12 . The experiments were conducted in glass reactors over $4 \mathrm{~h}$ at $30{ }^{\circ} \mathrm{C}$ under constant shaking, where $25 \mathrm{mg}$ of the adsorbent was added to $20 \mathrm{~mL}$ of $50 \mathrm{ppm}$ OII solution. The aliquots withdrawn from the reaction medium were quantified by UV-vis spectroscopy at $483 \mathrm{~nm}$. 

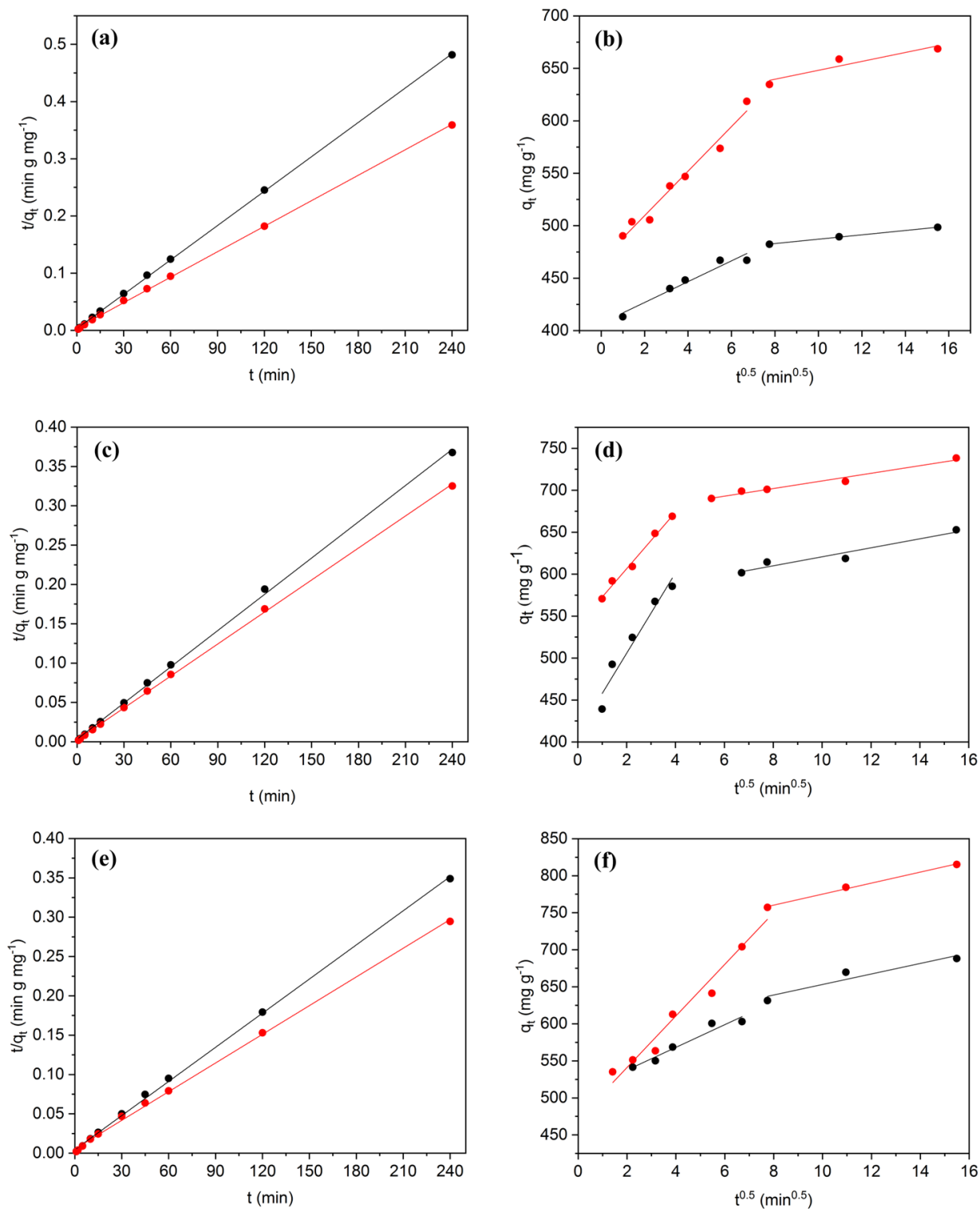

Figure 11. (a,c,e) Linear pseudo-second-order kinetics plots and (b,d,f) intraparticle diffusion plots for the adsorption of (a,b) MO; (c,d) OII; and $(\mathrm{e}, \mathrm{f}) \mathrm{CR}$ onto the as-synthesized (black) AA and (ref) NAA40. Adsorbent mass $=5 \mathrm{mg}, \mathrm{pH} 8, T=30^{\circ} \mathrm{C}$, and solution volume $=40 \mathrm{~mL}$.

The results recorded after $4 \mathrm{~h}$ of contact between the adsorbent and the adsorbate show that the presence of nickel in the aerogels has a crucial effect on the adsorption capacity (Figure 6). The lowest recorded adsorption was for the AAs, which was independent of $\mathrm{pH}$. Increasing the nickel content in the aerogels revealed an improvement in the adsorption capacity of the adsorbent, with slightly better results for NAA40 than for the other nickel-aluminum oxide aerogels. Figure $9 \mathrm{~b}$ shows that the best adsorption is seen for a $\mathrm{pH}$ of the solution around 8 . On the other hand, the $\mathrm{pH}$ was found to negatively affect adsorption on all adsorbents when it is at 12 . Monitoring the $\mathrm{pH}$ of the dye solution before and after the experiment revealed the changes that are correlated with the adsorbent composition as well as the initial $\mathrm{pH}$ (Figure 7). It was noticed that the final $\mathrm{pH}$ of the solution depends very much on the chemical composition of the adsorbent. In other words, the presence of the aerogels buffers the dye solution to $\mathrm{pH}$ values ranging between 4.6 and 7.8. This value increases by increasing the nickel content in the aerogel. This behavior does not apply to $\mathrm{pH} 12$, where the $\mathrm{pH}$ of the solution after $4 \mathrm{~h}$ of the reaction was found to range between 11.1 and 12.1, with an increase in the $\mathrm{pH}$ when increasing the nickel content.

The observed buffering effect could be attributed to some adsorbent surface reactions that are stabilizing the $\mathrm{pH}$ of the solution. Because the isoelectric points of alumina and nickelaluminum oxide were found to be 7.6 and 8.6, respectively, ${ }^{21}$ the surface of the adsorbents within the $\mathrm{pH}$ range 4.6-7.8 will be positively charged. At the same time, OII, which is an azodye having $2 \mathrm{p} K_{\mathrm{a}}$ values $\left(1\right.$ and 10.6), ${ }^{33}$ will exist within this $\mathrm{pH}$ range in its dominant monoprotonated form, thus creating a strong electrostatic attraction between the positively charged adsorbent and the negatively charged dye molecules, favoring the adsorption process. The weaker adsorption capacity recorded for the AAs is due to the lower isoelectric point of alumina compared to nickel-aluminum oxide. This makes the AAs to acquire a less dense surface-positive charge than their nickel-aluminum oxide peers.

3.2.2. Adsorption of Cationic and Anionic Dyes. The assynthesized NAA75 was randomly selected to be tested for the adsorption of different cationic ( $\mathrm{MB}, \mathrm{rh} 6 \mathrm{G}$, and $\mathrm{rhB}$ ) and 
Table 5. Thermodynamic Data for the Adsorption of Azo Dyes onto the As-Synthesized AA and NAA40

\begin{tabular}{|c|c|c|c|c|c|c|}
\hline dye & adsorbent & $T(\mathrm{~K})$ & $\Delta H^{0}\left(\mathrm{~kJ} \mathrm{~mol}^{-1}\right)$ & $\Delta S^{0}\left(\mathrm{~J} \mathrm{~K}^{-1} \mathrm{~mol}^{-1}\right)$ & $\Delta G^{0}\left(\mathrm{~kJ} \mathrm{~mol}^{-1}\right)$ & $E_{\mathrm{a}}\left(\mathrm{kJ} \mathrm{mol}^{-1}\right)$ \\
\hline \multirow[t]{6}{*}{ MO } & AA & 303 & -22.7 & -55.5 & -5.9 & 16.4 \\
\hline & & 313 & & & -5.3 & \\
\hline & & 323 & & & -4.8 & \\
\hline & NAA40 & 303 & -23.5 & -51.6 & -7.9 & 23.6 \\
\hline & & 313 & & & -7.3 & \\
\hline & & 323 & & & -6.8 & \\
\hline \multirow[t]{6}{*}{ OII } & $\mathrm{AA}$ & 303 & -15.8 & -28.7 & -7.1 & 9.2 \\
\hline & & 313 & & & -6.8 & \\
\hline & & 323 & & & -6.6 & \\
\hline & NAA40 & 303 & -45.8 & -117.2 & -10.3 & 12.7 \\
\hline & & 313 & & & -9.1 & \\
\hline & & 323 & & & -7.9 & \\
\hline \multirow[t]{6}{*}{ CR } & AA & 303 & -8.2 & 6.0 & -10.0 & 46.5 \\
\hline & & 313 & & & -10.1 & \\
\hline & & 323 & & & -10.1 & \\
\hline & NAA40 & 303 & -17.0 & -20.6 & -10.8 & 57.6 \\
\hline & & 313 & & & -10.6 & \\
\hline & & 323 & & & -10.3 & \\
\hline
\end{tabular}

anionic (MO, OII, and CR) dyes at $\mathrm{pH}$ 7. As shown in Figure 8 , the adsorption behavior is found to depend on the charge of the dye molecule in solution. The favored electrostatic attraction between the adsorbent and the adsorbate, in the case of anionic dyes, makes the adsorption occur extremely fast. For instance, the removal of OII from the solution after 2 min of contact time exceeds $96 \%$, whereas it did not exceed $7 \%$ in the case of the cationic dyes, where even after $4 \mathrm{~h}$, it reached a maximum of $16 \%$. This observation is in a good agreement with what was discussed previously and confirms that the adsorption process is monitored by the physical interaction between the adsorbent surface and the dye molecule.

3.2.3. Metal Release during Adsorption. The release of nickel and aluminum atoms during the adsorption process has been quantified by collecting samples from the aqueous medium to analyze the two elements using AAS. For that purpose, adsorption experiments have been conducted at various $\mathrm{pH}$ values, where NAA40 was used as an adsorbent in a $50 \mathrm{ppm}$ OII solution (mass of adsorbent $=25 \mathrm{mg}$; $\mathrm{T}=30^{\circ} \mathrm{C}$; $V=20 \mathrm{~mL}$ ). The samples taken after 2 and $240 \mathrm{~min}$ were centrifuged and filtered on microfilters before analysis. The collected data show that there is no release of aluminum from NAA40 for any $\mathrm{pH}$ value equal to or lower than 10 (Table 2). A slight release was observed at $\mathrm{pH} 11$ after $4 \mathrm{~h}$; however, this release remarkably increases at $\mathrm{pH} 12$. The release of aluminum is expected to be in the form of $\mathrm{Al}(\mathrm{OH})_{4}{ }^{-}$produced under basic conditions. Conversely, some nickel was released in the medium immediately after the start of the reaction and it increased over time. In an opposite trend to aluminum, the release of nickel was found to decrease when the $\mathrm{pH}$ increases, until no release observed at $\mathrm{pH}$ values 11 and 12 . This behavior is due to the chemical dissolution of $\mathrm{NiO}$ in acidic media, ${ }^{34}$ leading to the soluble $\mathrm{Ni}^{2+}$ and $\mathrm{NiOH}^{+}$ions as per the following chemical reaction

$$
\mathrm{NiO}+(2-b) \mathrm{H}^{+} \rightleftharpoons \mathrm{Ni}(\mathrm{OH})_{b}^{+(2-b)}+(1-b) \mathrm{H}_{2} \mathrm{O}
$$

Taking into consideration the kinetics of the nickel and aluminum release, we found out that the experiments conducted at $\mathrm{pH} 8$ revealed the lowest. Similar experiments conducted with NAA75 showed identical trends; however, the release of nickel was slightly greater than for NAA40 (3 and 7\% after 2 and $240 \mathrm{~min}$, respectively). Accordingly, NAA40 aerogels have been selected for the next series of adsorption experiments that were conducted at $\mathrm{pH} 8$. AAs were also tested as a reference to understand the effect of nickel in NAA40.

3.2.4. Effect of the Calcination of the Aerogels on Adsorption. Adsorption tests of OII have been conducted using AA and NAA adsorbents either as-synthesized or after being calcined at 200,500 , or $800{ }^{\circ} \mathrm{C}$. The experiments have been performed at $\mathrm{pH} 8$ and were followed over $4 \mathrm{~h}$. The results revealed similar trends for the adsorbents as-synthesized and after being calcined at $200{ }^{\circ} \mathrm{C}$, with a major difference for the AA, which showed an improvement in its adsorption capacity after being calcined at $200{ }^{\circ} \mathrm{C}$ (Figure 9). It is important to mention that the adsorption equilibrium for these aerogels was reached after $2 \mathrm{~min}$ of contact time between the adsorbent and the adsorbate. On the other hand, the calcination of the aerogels at 500 and $800{ }^{\circ} \mathrm{C}$ led to a drastic decrease in the adsorption kinetics for all aerogels, which affected the adsorption capacity even after $4 \mathrm{~h}$. The decrease in the adsorption rate could be partly due to the decrease in the SSA and the pore volume after calcination. This makes the adsorption sites less abundant and the diffusion of the dye molecules within the pore of the calcined aerogel harder. However, it is not the only reason because the observed trends do not correlate with the trend in the decrease of SSA and $V_{\mathrm{p}}$. This suggests an effect on the adsorbate-adsorbent interaction of the amorphous-crystalline transitions that took place at high calcination temperatures.

Because the adsorption process was found to be extremely fast under the investigated conditions and not allowing for accurate differentiation between alumina and nickel-aluminum oxide aerogels, a new series of adsorption tests were conducted. The mass of the adsorbent was reduced to 5 and 10 $\mathrm{mg}$, and the volume of the OII solution was increased to 40 $\mathrm{mL}$. The obtained results showed a large difference between AA and NAA40, confirming the effect of nickel on improving the uptake of the dye molecule by the adsorbent, for $5 \mathrm{mg}$ of adsorbent as well as for $10 \mathrm{mg}$ (Figure 10).

3.2.5. Effect of Initial Dye Concentration and Adsorption Isotherms. The adsorption capacity of the as-synthesized AA 
and NAA40 for the three azo dyes (OII, MO, and CR) was investigated as a function of the initial dye concentration. The initial dye concentration was selected to range between 10 and $1000 \mathrm{ppm}$, the $\mathrm{pH}$ value was set at 8 , the temperature was set at $30{ }^{\circ} \mathrm{C}$, the initial adsorbent dose was $5 \mathrm{mg}$, and the contact time was $24 \mathrm{~h}$ to make sure that the equilibrium is reached for all reactions. The collected samples were filtered after centrifugation to guarantee the complete removal of the aerogel particles.

Figure S5 in the Supporting Information shows the variation in the percent removal and equilibrium adsorption capacity $q_{\mathrm{e}}$ of AA and NAA40 for the three azo dyes. At low concentrations of dyes, AA and NAA40 exhibit very similar adsorption capacities at equilibrium; however, at higher dye concentrations, NAA40 exhibits higher values. Langmuir, ${ }^{35}$ Freundlich, ${ }^{36}$ Dubinin-Radushkevich, ${ }^{37}$ Redlich-Peterson, ${ }^{38}$ and Sips ${ }^{39,40}$ isotherm models were used to fit the experimental data. The results for the three azo dyes given in Table 3 revealed that they all fit perfectly the Sips isotherm, which combines the Langmuir and Freundlich isotherms. The calculated maximum monolayer capacities $\left(q_{\max }\right)$ for the AA are 745,1181 , and $1154 \mathrm{mg} \mathrm{g}^{-1}$ for MO, OII, and CR, respectively. The calculated $q_{\max }$ values for NAA40 are 900, 1484, and $1660 \mathrm{mg} \mathrm{g}^{-1}$ for MO, OII, and CR, respectively. These values show that the maximum adsorption capacities of NAA40 for OII and MO put this adsorbent among the best ones, as reported in the literature. Besides, the calculated $q_{\max }$ values for AA and NAA40 as adsorbents for CR exceed all values reported for $\mathrm{NiO}$-based and $\mathrm{Al}_{2} \mathrm{O}_{3}$-based adsorbents for CR (Table 4). ${ }^{41-55}$

3.2.6. Adsorption Kinetics. The kinetic study of adsorption was investigated for the three azo dyes at 30,40 , and $50{ }^{\circ} \mathrm{C}$. In order to collect the highest number of useful data points, 100 ppm was used as the initial dye concentration, and $5 \mathrm{mg}$ of each adsorbent was used (AA and NAA40) for the experiments conducted at $\mathrm{pH}$ 8. By fitting the experimental data with various kinetic models, we found out that adsorption of the dyes onto AA and NAA40 obeys pseudo-second-order kinetics expressed by the following equation

$$
\frac{t}{q_{t}}=\frac{t}{q_{\mathrm{e}}}+\frac{1}{q_{\mathrm{e}}^{2}}
$$

where $q_{t}$ is the amount of the dye adsorbed at a time $t$ (mg $\left.\mathrm{g}^{-1}\right)$ and $k_{2}$ is the pseudo-second-order rate constant $\left(\mathrm{g} \mathrm{mg}^{-1}\right.$ $\left.\min ^{-1}\right)$. The correlation coefficients $R^{2}$ are found to be greater than 0.999 (Figure 11a,c,e).

This finding suggests that the adsorption mechanism depends on the adsorbent as well as the adsorbate and involves a chemisorption process in addition to physisorption. The retrieved $k_{2}$ values from the kinetic plots (Supporting Information Table S2) were used in calculating the activation energy of adsorption $\left(E_{\mathrm{a}}\right)$ of the three dyes onto AA and NAA40 using the Arrhenius equation. The calculated $E_{\mathrm{a}}$ values given in Table 5 range between 9.2 and $57.6 \mathrm{~kJ} \mathrm{~mol}^{-1}$, thus suggesting a dominant physisorption process for the adsorption of OII and MO because their corresponding activation energies fall within the range between 5 and $40 \mathrm{~kJ}$ $\mathrm{mol}^{-1}$. The activation energies for the adsorption of CR are 46.5 and $57.6 \mathrm{~kJ} \mathrm{~mol}^{-1}$; this reveals that this adsorption process involves chemical interactions in addition to the physical ones. ${ }^{56}$ The difference in the adsorption process between the various studied dyes could be due to the difference in their chemical structure, where $\mathrm{CR}$ is much bigger than the two other dyes and it has two azo and sulfonic groups, whereas OII and MO contain only one.

To understand the adsorption mechanism and to investigate the possibility of intraparticle diffusion, the following equation was used ${ }^{57}$

$$
q_{t}=k_{\mathrm{p}} t^{0.5}+C
$$

where $k_{\mathrm{p}}$ is the intraparticle diffusion rate constant $\left(\mathrm{mg} \mathrm{g}^{-1}\right.$ $\left.\min ^{-0.5}\right)$.

The plot of $q_{t}$ versus $t^{0.5}$ showed dual linearity, indicating that the adsorption process takes place in two steps (Figure $11 \mathrm{~b}, \mathrm{~d}, \mathrm{f})$. The first corresponds to the diffusion through the liquid thin layer surrounding the solid particle known by boundary layer diffusion, whereas the second corresponds to the diffusion within the liquid included in the pore known by the intraparticle diffusion. Because the linear plots do not pass through the origin, the intraparticle diffusion is not solely the rate-determining step. The process is also governed by layer diffusion.

3.2.7. Thermodynamic Study. The calculation of the change in the free Gibbs energy $\Delta G^{0}$, the enthalpy $\Delta H^{0}$, and the entropy $\Delta S^{0}$ of adsorption was done using the van't Hoff equation

$$
\ln K_{\mathrm{d}}=-\frac{\Delta H^{0}}{R} \frac{1}{T}+\frac{\Delta S^{0}}{R}
$$

where the equilibrium distribution constant $K_{d}$ is calculated as follows

$$
K_{\mathrm{d}}=\frac{q_{\mathrm{e}}}{C_{\mathrm{e}}}
$$

The values of $\Delta G^{0}, \Delta H^{0}, \Delta S^{0}$, and $E_{\text {a }}$ given in Table 5 show that the adsorption process is exothermic and thermodynamically favored. The negative values for the change in the entropy suggest that the adsorption process brings more order to the adsorbent-adsorbate couple, except for the adsorption of CR onto AA, where a slight positive $\Delta S^{0}$ is observed.

\section{CONCLUSIONS}

This study showed that nickel-aluminum oxide aerogels prepared according to the one-pot sol-gel process are highly efficient and are fast adsorbents for anionic azo dyes from a simulated wastewater. The structural and textural characterization of the aerogels before and after calcination disclosed their mesoporous nature with an effect of the nickel content and the heat treatment on the SSA, pore volume, and crystallinity of the material. Introducing nickel in the structure leads to the formation of spinel nickel aluminate by calcination. The surface morphology, depicted by nitrogen adsorption and confirmed by SEM, reveals that the aerogels consist of aggregates of spheres, where the incorporation of nickel atoms in the structure is dominant over aluminum, except for the materials containing a high nickel-to-aluminum molar ratio. Nickel-aluminum oxide aerogels exhibit selectivity toward the adsorption of anionic dyes. Doping the AAs with nickel showed a tremendous improvement in the behavior of the adsorbent, whereas the heat treatment at high temperatures negatively affected the adsorptive capacity of the aerogels. The exothermic adsorption of azo dyes onto alumina and nickelaluminum oxide aerogels revealed pseudo-second-order kinetics, suggesting a mixed process involving chemical and 
physical interactions. The exceptionally high maximum monolayer capacities $\left(q_{\max }\right)$ for the nickel-aluminum oxide aerogel with $40 \%$ nickel (NAA40) put it among the best adsorbents for azo dyes. $q_{\max }$ is $900 \mathrm{mg} \mathrm{g}^{-1}$ for MO, $1484 \mathrm{mg}$ $\mathrm{g}^{-1}$ for OII, and $1660 \mathrm{mg} \mathrm{g}^{-1}$ for CR.

\section{ASSOCIATED CONTENT}

\section{SI Supporting Information}

The Supporting Information is available free of charge at https://pubs.acs.org/doi/10.1021/acsomega.0c03828.

Nitrogen adsorption-desorption isotherms and pore size distributions for AA and NAA75, FTIR spectra of as-synthesized and calcined alumina and nickelaluminum oxide aerogels, powder X-ray diffractograms for NAA50 and NAA75 calcined at $500{ }^{\circ} \mathrm{C}$, pictures of calcined nickel-aluminum oxide aerogels at $800{ }^{\circ} \mathrm{C}$, plot of the effect of initial dye concentration variation on the $\%$ removal of the dye and the equilibrium adsorption capacity on the adsorbent, calculated molar metal ratios from the AAS measurements for alumina and nickelaluminum oxide aerogels, and pseudo-second-order rate constants calculated for the adsorption of azo dyes onto as-synthesized AA and NAA40 (PDF)

\section{AUTHOR INFORMATION}

\section{Corresponding Author}

Houssam El-Rassy - Department of Chemistry, American University of Beirut, 11072020 Beirut, Lebanon; 아. orcid.org/ 0000-0003-4756-501X; Phone: +961-1-350000;

Email: Houssam.Rassy@aub.edu.lb

\section{Author \\ Maya Chaaban - Department of Chemistry, American University of Beirut, 11072020 Beirut, Lebanon}

Complete contact information is available at: https://pubs.acs.org/10.1021/acsomega.0c03828

\section{Notes}

The authors declare no competing financial interest.

\section{ACKNOWLEDGMENTS}

The authors gratefully acknowledge the financial support by the University Research Board (URB) at the American University of Beirut. The authors are also thankful for the Kamal A. Shair Central Research Science Lab (KAS CRSL) of the Faculty of Arts and Sciences at AUB.

\section{REFERENCES}

(1) Brinker, C. J.; Scherer, G. W. Sol-Gel Science. The Physics and Chemistry of Sol-Gel Processing; Academic Press: New York, 1990.

(2) Livage, J.; Henry, M.; Sanchez, C. Sol-gel chemistry of transition metal oxides. Prog. Solid State Chem. 1988, 18, 259-341.

(3) Poco, J. F.; Satcher, J. H.; Hrubesh, L. W. Synthesis of high porosity, monolithic alumina aerogels. J. Non-Cryst. Solids 2001, 285, $57-63$.

(4) Gash, A. E.; Tillotson, T. M.; Satcher, J. H., Jr.; Hrubesh, L. W.; Simpson, R. L. New sol-gel synthetic route to transition and maingroup metal oxide aerogels using inorganic salt precursors. J. NonCryst. Solids 2001, 285, 22-28.

(5) Rai, D.; Sass, B. M.; Moore, D. A. Chromium(III) hydrolysis constants and solubility of chromium(III) hydroxide. Inorg. Chem. $1987,26,345-349$.
(6) Baumann, T. F.; Gash, A. E.; Chinn, S. C.; Sawvel, A. M.; Maxwell, R. S.; Satcher, J. H. Synthesis of High-Surface-Area Alumina Aerogels without the Use of Alkoxide Precursors. Chem. Mater. 2005, 17, 395-401.

(7) Ren, L.; Li, X.; He, H. Alumina Particles Are Snowballing with Propylene Oxide-Synthesis of Alumina Aerogels with Free Adjustable Particle and Pore Sizes. ChemistrySelect 2016, 1, 1072-1075.

(8) Knez, Ž.; Novak, Z. Adsorption of Water Vapor on Silica, Alumina, and Their Mixed Oxide Aerogels. J. Chem. Eng. Data 2001, $46,858-860$.

(9) Khaleel, A. A.; Klabunde, K. J. Characterization of Aerogel Prepared High-Surface-Area Alumina: In Situ FTIR Study of Dehydroxylation and Pyridine Adsorption. Chem. - Eur. J. 2002, 8, 3991-3998.

(10) Yang, W.; Dou, X.; Li, Y.; Mohan, D.; Pittman, C. U.; Ok, Y. S. Performance and mass transfer of aqueous fluoride removal by a magnetic alumina aerogel. RSC Adv. 2016, 6, 112988-112999.

(11) Zhao, W.; Zhu, J.; Wei, W.; Ma, L.; Zhu, J.; Xie, J. Comparative study of modified/non-modified aluminum and silica aerogels for anionic dye adsorption performance. RSC Adv. 2018, 8, 2912929140.

(12) Karami, D.; Mahinpey, N. Utilization of Alumina Aerogel as High Surface Area Support for the Fabrication of Oxygen Carriers in the Chemical Looping Combustion Process. Energy Fuels 2019, 33, $5408-5414$

(13) Moura-Nickel, C. D.; Costa, R. L.; Salvador Ferreira, S. R.; de Fátima Peralta Muniz Moreira, R.; José, H. J. $\mathrm{NiY}_{2} \mathrm{O}_{3} \mathrm{Al}_{2} \mathrm{O}_{3}$ aerogel catalysts with high coke deposition resistance for syngas production by biogas reforming. Int. J. Hydrogen Energy 2019, 44, 11861-11871.

(14) Gao, B.; Wang, I.-W.; Ren, L.; Haines, T.; Hu, J. Catalytic Performance and Reproducibility of $\mathrm{Ni} / \mathrm{Al}_{2} \mathrm{O}_{3}$ and $\mathrm{Co} / \mathrm{Al}_{2} \mathrm{O}_{3}$ Mesoporous Aerogel Catalysts for Methane Decomposition. Ind. Eng. Chem. Res. 2019, 58, 798-807.

(15) Hossain, M. Z.; Chowdhury, M. B. I.; Jhawar, A. K.; Charpentier, P. A. Supercritical water gasification of glucose using bimetallic aerogel $\mathrm{Ru}-\mathrm{Ni}-\mathrm{Al}_{2} \mathrm{O}_{3}$ catalyst for $\mathrm{H}_{2}$ production. Biomass Bioenergy 2017, 107, 39-51.

(16) Zhao, X.; Cao, Y.; Li, H.; Zhang, J.; Shi, L.; Zhang, D. Sc promoted and aerogel confined $\mathrm{Ni}$ catalysts for coking-resistant dry reforming of methane. RSC Adv. 2017, 7, 4735-4745.

(17) Yoo, J.; Bang, Y.; Han, S. J.; Park, S.; Song, J. H.; Song, I. K. Hydrogen production by tri-reforming of methane over nickelalumina aerogel catalyst. J. Mol. Catal. A: Chem. 2015, 410, 74-80.

(18) Zhang, P.; Ma, X.; Guo, Y.; Cheng, Q.; Yang, L. Size-controlled synthesis of hierarchical $\mathrm{NiO}$ hollow microspheres and the adsorption for Congo red in water. Chem. Eng. J. 2012, 189-190, 188-195.

(19) Li, M.; Si, Z.; Wu, X.; Weng, D.; Kang, F. Facile synthesis of hierarchical porous gamma- $\mathrm{Al}_{2} \mathrm{O}_{3}$ hollow microspheres for water treatment. J. Colloid Interface Sci. 2014, 417, 369-378.

(20) Liu, X.; Niu, C.; Zhen, X.; Wang, J.; Su, X. Novel approach for synthesis of boehmite nanostructures and their conversion to aluminum oxide nanostructures for remove Congo red. J. Colloid Interface Sci. 2015, 452, 116-125.

(21) Lei, C.; Zhu, X.; Le, Y.; Zhu, B.; Yu, J.; Ho, W. Hierarchically porous $\mathrm{NiO}-\mathrm{Al} 2 \mathrm{O} 3$ nanocomposite with enhanced Congo red adsorption in water. RSC Adv. 2016, 6, 10272-10279.

(22) Zhao, J.; Zha, J.; Lu, H.; Yang, C.; Yan, K.; Meng, X. Cauliflower-like $\mathrm{Ni} / \mathrm{NiO}$ and $\mathrm{NiO}$ architectures transformed from nickel alkoxide and their excellent removal of Congo red and $\mathrm{Cr}(\mathrm{VI})$ ions from water. RSC Adv. 2016, 6, 103585-103593.

(23) Rong, X.; Qiu, F.; Qin, J.; Zhao, H.; Yan, J.; Yang, D. A facile hydrothermal synthesis, adsorption kinetics and isotherms to Congo Red azo-dye from aqueous solution of $\mathrm{NiO} /$ graphene nanosheets adsorbent. J. Ind. Eng. Chem. 2015, 26, 354-363.

(24) Brunauer, S.; Emmett, P. H.; Teller, E. Adsorption of gases in multimolecular layers. J. Am. Chem. Soc. 1938, 60, 309-319.

(25) Barrett, E. P.; Joyner, L. G.; Halenda, P. P. The determination of pore volume and area distributions in porous substances. I. 
Computations from nitrogen isotherms. J. Am. Chem. Soc. 1951, 73, 373-380.

(26) Thommes, M.; Kaneko, K.; Neimark, A. V.; Olivier, J. P.; Rodriguez-Reinoso, F.; Rouquerol, J.; Sing, K. S. W. Physisorption of gases, with special reference to the evaluation of surface area and pore size distribution (IUPAC Technical Report). Plants Human Health Aquat. Life 2015, 87, 1051.

(27) Krompiec, S.; Mrowiec-Białoń, J.; Skutil, K.; Dukowicz, A.; Pająk, L.; Jarzębski, A. B. Nickel-alumina composite aerogel catalysts with a high nickel load: a novel fast sol-gel synthesis procedure and screening of catalytic properties. J. Non-Cryst. Solids 2003, 315, 297303.

(28) Pierre, A. C. Sol-Gel Technology. Kirk Othmer Encyclopedia of Chemical Technology, 5th ed.; Wiley Intersciences, 2007; Vol. 23, pp 53-84.

(29) Socrates, G. Infrared and Raman Characteristic Group Frequencies: Tables and Charts, 3rd ed.; Wiley, 2001.

(30) Bhagat, S. D.; Oh, C.-S.; Kim, Y.-H.; Ahn, Y.-S.; Yeo, J.-G. Methyltrimethoxysilane based monolithic silica aerogels via ambient pressure drying. Microporous Mesoporous Mater. 2007, 100, 350-355.

(31) Kang, S.-K.; Choi, S.-Y. Synthesis of low-density silica gel at ambient pressure: Effect of heat treatment. J. Mater. Sci. 2000, 35, 4971-4976.

(32) Osaki, T.; Horiuchi, T.; Sugiyama, T.; Suzuki, K.; Mori, T. $\mathrm{NiO}-\mathrm{Al}_{2} \mathrm{O}_{3}$ aerogel from $\left(\mathrm{CH}_{2} \mathrm{O}\right)_{2} \mathrm{Ni}$ and $\mathrm{AlOOH}$ sol. J. Non-Cryst. Solids 1998, 225, 111-114.

(33) Bourikas, K.; Stylidi, M.; Kondarides, D. I.; Verykios, X. E. Adsorption of Acid Orange 7 on the Surface of Titanium Dioxide. Langmuir 2005, 21, 9222-9230.

(34) Tremaine, P. R.; Leblanc, J. C. The solubility of nickel oxide and hydrolysis of $\mathrm{Ni}^{2+}$ in water to $573 \mathrm{~K}$. J. Chem. Thermodyn. 1980, $12,521-538$.

(35) Langmuir, I. The adsorption of gases on plane surfaces of glass, mica and platinum. J. Am. Chem. Soc. 1918, 40, 1361-1403.

(36) Freundlich, H. Of the adsorption of gases. Section II. Kinetics and energetics of gas adsorption. Introductory paper to section II. Trans. Faraday Soc. 1932, 28, 195-201.

(37) Dubinin, M. M.; Radushkevich, L. V. The equation of the characteristic curve of activated charcoal. Dokl. Akad. Nauk SSSR 1947, 55, 327-329.

(38) Redlich, O.; Peterson, D. L. A Useful Adsorption Isotherm. J. Phys. Chem. 1959, 63, 1024.

(39) Sips, R. On the Structure of a Catalyst Surface. J. Chem. Phys. 1948, 16, 490-495.

(40) Sips, R. On the Structure of a Catalyst Surface. II. J. Chem. Phys. 1950, 18, 1024-1026.

(41) Xiao, L.; Xiong, Y.; Wen, Z.; Tian, S. Adsorption behavior of one-dimensional coordination polymers $[\mathrm{Cu} \text { (bipy) } \mathrm{X}]_{\mathrm{n}}\left(\mathrm{X}=2 \mathrm{Cl}^{-}\right.$and $\left.\mathrm{SO}_{4}^{2-}\right)$ toward acid orange 7 and methyl orange. RSC $A d v .2015,5$, 61593-61600.

(42) Erdem, M.; Dikişler, Ö.; Erdem, B. Removal of Orange II from Aqueous Solutions UsingN-Vinyl Imidazole-based Hydrogels as Adsorbents. Chem. Eng. Commun. 2016, 203, 1403-1412.

(43) Yu, H.; Wang, T.; Dai, W.; Li, X.; Hu, X.; Ma, N. Single and bicomponent anionic dyes adsorption equilibrium studies on magnolia-leaf-based porous carbons. RSC Adv. 2015, 5, 6397063977.

(44) Mustapha Bouhent, M.; Derriche, Z.; Denoyel, R.; Prevot, V.; Forano, C. Thermodynamical and structural insights of orange II adsorption by $\mathrm{MgRAlNO}_{3}$ layered double hydroxides. J. Solid State Chem. 2011, 184, 1016-1024.

(45) Sobhana, S. S. L.; Bogati, D. R.; Reza, M.; Gustafsson, J.; Fardim, P. Cellulose biotemplates for layered double hydroxides networks. Microporous Mesoporous Mater. 2016, 225, 66-73.

(46) Gao, J.; Zhang, L.; Liu, X.; Zhang, W. Hierarchically structured, well-dispersed $\mathrm{Ti}^{4+}$ cross-linked chitosan as an efficient and recyclable sponge-like adsorbent for anionic azo-dye removal. RSC Adv. 2016, 6, 106260-106267.
(47) Ma, J.; Zou, J.; Cui, B.; Yao, C.; Li, D. Adsorption of Orange II dye from aqueous solutions using phosphoric-acid modified clam shell powder. Desalin. Water Treat. 2013, 51, 6536-6544.

(48) Sun, X.-F.; Guo, B.-B.; He, L.; Xia, P.-F.; Wang, S.-G. Electrically accelerated removal of organic pollutants by a threedimensional graphene aerogel. AIChE J. 2016, 62, 2154-2162.

(49) García, E.; Medina, R.; Lozano, M.; Hernández Pérez, I.; Valero, M.; Franco, A. Adsorption of Azo-Dye Orange II from Aqueous Solutions Using a Metal-Organic Framework Material: IronBenzenetricarboxylate. Materials 2014, 7, 8037-8057.

(50) Abramian, L.; El-Rassy, H. Adsorption kinetics and thermodynamics of azo-dye Orange II onto highly porous titania aerogel. Chem. Eng. J. 2009, 150, 403-410.

(51) Arshadi, M. Adsorptive removal of an organic dye from aqueous solution with a nano-organometallic: Kinetic, thermodynamic and mechanism. J. Mol. Liq. 2015, 211, 899-908.

(52) Chen, Y.; Jing, C.; Zhang, X.; Jiang, D.; Liu, X.; Dong, B.; Feng, L.; Li, S.; Zhang, Y. Acid-salt treated CoAl layered double hydroxide nanosheets with enhanced adsorption capacity of methyl orange dye. J. Colloid Interface Sci. 2019, 548, 100-109.

(53) Haitham, K.; Razak, S.; Nawi, M. A. Kinetics and isotherm studies of methyl orange adsorption by a highly recyclable immobilized polyaniline on a glass plate. Arabian J. Chem. 2019, 12, $1595-1606$.

(54) Zheng, Y.; Cheng, B.; You, W.; Yu, J.; Ho, W. 3D hierarchical graphene oxide- $\mathrm{NiFe} \mathrm{LDH}$ composite with enhanced adsorption affinity to Congo red, methyl orange and $\mathrm{Cr}(\mathrm{VI})$ ions. J. Hazard. Mater. 2019, 369, 214-225.

(55) Wang, B.; Yang, X.; Ma, L.; Zhai, L.; Xuan, J.; Liu, C.; Bai, Z. Ultra-high efficient $\mathrm{pH}$ induced selective removal of cationic and anionic dyes from complex coexisted solution by novel amphoteric biocomposite microspheres. Sep. Purif. Technol. 2020, 231, 115922.

(56) Nollet, H.; Roels, M.; Lutgen, P.; Van der Meeren, P.; Verstraete, W. Removal of PCBs from wastewater using fly ash. Chemosphere 2003, 53, 655-665.

(57) Weber, W. J.; Carrell, J. C. Kinetics of Adsorption on Carbon from Solution. J. Sanit. Eng. Div., Am. Soc. Civ. Eng. 1963, 89, 31-60. 